\title{
A Dose-Dependent Relationship between Exposure to a Street-Based Drug Scene and Health-Related Harms among People Who Use Injection Drugs
}

Kora DeBeck, Evan Wood, Ruth Zhang, Jane Buxton, Julio Montaner, and Thomas Kerr

\begin{abstract}
While the community impacts of drug-related street disorder have been well described, lesser attention has been given to the potential health and social implications of drug scene exposure on street-involved people who use illicit drugs. Therefore, we sought to assess the impacts of exposure to a street-based drug scene among injection drug users (IDU) in a Canadian setting. Data were derived from a prospective cohort study known as the Vancouver Injection Drug Users Study. Four categories of drug scene exposure were defined based on the numbers of hours spent on the street each day. Three generalized estimating equation (GEE) logistic regression models were constructed to identify factors associated with varying levels of drug scene exposure (26, 6-15, over 15 hours) during the period of December 2005 to March 2009. Among our sample of 1,486 IDU, at baseline, a total of 314 (21\%) fit the criteria for high drug scene exposure ( $>15$ hours per day). In multivariate GEE analysis, factors significantly and independently associated with high exposure included: unstable housing (adjusted odds ratio $[A O R]=9.50 ; 95 \%$ confidence interval $[C I], 6.36-14.20)$; daily crack use (AOR= 2.70; 95\% CI, 2.07-3.52); encounters with police (AOR $=2.11$; 95\% CI, 1.62-2.75); and being a victim of violence $(A O R=1.49 ; 95 \% C I, 1.14-1.95)$. Regular employment $(A O R=$ $0.50 ; 95 \% \mathrm{CI}, 0.38-0.65)$, and engagement with addiction treatment $(A O R=0.58 ; 95 \%$ CI, 0.45-0.75) were negatively associated with high exposure. Our findings indicate that drug scene exposure is associated with markers of vulnerability and higher intensity addiction. Intensity of drug scene exposure was associated with indicators of vulnerability to harm in a dose-dependent fashion. These findings highlight opportunities for policy interventions to address exposure to street disorder in the areas of employment, housing, and addiction treatment.
\end{abstract}

KEYWORDS Injection drug use, Illicit drug scenes, Low threshold employment, Unstable housing

\section{INTRODUCTION}

In many urban areas globally, street disorder related to the use and trade of illicit drugs is a growing public policy concern. ${ }^{1-3}$ Common markers of drug-related street disorder include the consumption of illegal drugs in public areas and public intoxication (i.e., loitering or socializing in public spaces while under the influence of

DeBeck, Wood, Zhang, Montaner, and Kerr are with the British Columbia Centre for Excellence in HIV/ AIDS, Vancouver, BC, Canada; Wood, Montaner, and Kerr are with the Division of AIDS, Department of Medicine, University of British Columbia, Vancouver, BC, Canada; Buxton is with the School of Population and Public Health, University of British Columbia, Vancouver, BC, Canada.

Correspondence: Thomas Kerr, British Columbia Centre for Excellence in HIV/AIDS, 608-1081 Burrard Street, Vancouver, BC V6Z 1Y6, Canada. (E-mail: uhri-tk@cfenet.ubc.ca) 
drugs). ${ }^{4,5}$ In addition, activities including street-level drug dealing, street-based sex work, panhandling, and engaging in "binning," recycling, salvaging, and unsanctioned street vending are examples of everyday income-generation strategies used by many street-based drug users which further contribute to street disorder. ${ }^{6-9}$ The physical locations where these disorderly activities are highly concentrated are often referred to as "drug scenes" and are widely recognized and well-described in many urban areas, including Vancouver, Canada, where a large open drug scene has persisted for decades. ${ }^{10,11}$

To date, the harmful impacts of drug-related street disorder are most frequently discussed in reference to their negative effects on surrounding communities. ${ }^{2,3}$ It has been reported that when questioned, a high proportion of urban citizens rank street disorder as a top concern in their community, often above very serious crimes including homicide, sexual assault, and robbery. ${ }^{1-3}$ Indeed, the atmosphere of streetlevel drug dealing can be intimidating for the general public and may discourage the use of public spaces in the vicinity of street-based drug scenes. ${ }^{12}$ High levels of street disorder have also been linked to depressing retail activity and economic investment in surrounding areas. ${ }^{1,2,13,14}$

While the community impacts of drug-related street disorder are generally well understood, lesser attention has been given to the potential health and social impacts that being exposed to and immersed in street-based drug scenes has on streetinvolved people who use illicit drugs. ${ }^{15}$ Existing public health research has documented a wide range of health risks associated with engaging in specific disorderly activities, such as street-based sex work, ${ }^{6,16}$ the use of injection drugs in public areas, ${ }^{4,17,18}$ and street-level drug dealing; ${ }^{7}$ however, these studies focused on specific behaviors and did not consider the role that exposure to drug scenes itself may play in shaping health behaviors and outcomes.

To address this gap, we sought to assess whether varying levels of drug scene exposure were associated with markers of vulnerability to harm and adverse health outcomes.

\section{METHODS}

Data for this study were derived from the Vancouver Injection Drug Users Study, which is a community recruited prospective cohort that began enrolling participants in May 1996. The protocol and methodology for this study have been described in detail previously. ${ }^{19,20}$ In brief, to be eligible, participants had to have injected drugs in the previous month, live in the greater Vancouver region, and provide written informed consent. At baseline and semi-annually, participants complete an interviewer-administered questionnaire which elicits information about drug use and other behavioral patterns, as well as income-generation practices, engagement with medical and addiction treatment services, and encounters with law enforcement and other related experiences with the criminal justice system. At each study visit, participants also meet with a study nurse and, as appropriate, receive referrals for any necessary health and social services. Study participants receive a stipend in the amount of $\$ 20 \mathrm{CDN}$ for their time at the conclusion of each study visit. The study has received ethical approval from Providence Health Care and the University of British Columbia's Research Ethics Board. The present study is restricted to those participants seen for study follow-up during the period of December 2005 to March 2009, as the measure for our outcome of interest was available only for this period. 
The primary outcome of interest for this analysis was "drug scene exposure" broadly defined as spending time on the street in Vancouver's drug use epicenter, which is a well-described and defined area of the city referred to as the "Downtown Eastside." 20 Our measure for this variable was based on responses to the question: "On average, how many hours a day do you spend on the street?" To capture exposure to drug scenes and not general exposure to city streets, we limited our measure of drug scene exposure to participants that resided in or frequently visited (daily or two to three times a week) Vancouver's drug use epicenter. Because we were interested in assessing whether differing levels of drug scene exposure were associated risk behavior and harm, we created four categories of drug scene exposure. We defined our reference category of "no exposure" to include all individuals who did not reside in or frequently visit Vancouver's drug use epicenter, as well as individuals who reported spending no more than an average of 1 hour or less on the street each day over the last 6 months. After examining the distribution of one small cross-sectional sample of reports of the number of hours spent on the street, we divided the responses into three groups of similar size. These are referred to as the "low," "moderate," and "high" exposure groups, which included individuals that resided in or frequently visited Vancouver's drug use epicenter and spent on average between 2 and 6, 7 and 15, and more than 15 hours on the street each day over the last 6 months, respectively.

Explanatory variables of interest included socio-demographic information: gender (female vs. male), age (per year older), and Aboriginal ancestry (yes vs. no). We considered a number of factors that are generally understood to contribute to drug scenes and street disorder, but are not by definition street disorder, and are in themselves markers of vulnerability to harms and adverse health outcomes. They included unstable housing, defined as living in a single occupancy room in hotel, a treatment or recovery house, jail, shelter or hostel, or having no fixed address for the last 6 months (yes vs. no); sex trade involvement, defined as exchanging sex for money, shelter, drugs, or other commodities (yes vs. no); and participation in drug dealing (yes vs. no). Drug use patterns and other factors considered to be markers of vulnerability to harm and adverse health outcomes were also of interest and they included: daily cocaine injection (yes vs. no); daily heroin injection (yes vs. no); daily crack cocaine smoking (yes vs. no), non-fatal overdose (yes vs. no), syringe sharing, defined as borrowing or lending syringes already used by someone else to inject drugs (yes vs. no); encounters with police in the last month, defined as being questioned, searched, or stopped by police (yes vs. no); being a victim of violence, defined as being physically assaulted (yes vs. no); having multiple sex partners (yes vs. no); and engaging in any unprotected sex (yes vs. no). Other factors considered included: having regular employment, defined as having a regular or temporary job (yes vs. no); and participation in any addiction treatment program, defined as reporting being enrolled in methadone treatment, a detoxification program, a recovery house, a residential addiction treatment center, or engaging with an addictions counselor or participating in peer support programs such as Narcotics Anonymous (yes vs. no). Unless otherwise stated, all behavioral variables refer to the previous 6 months. To account for a potential seasonal influence on the amount of time individuals spend on the street, we also included a categorical variable representing the month that participants completed our study. This helped ensure that our analysis adjusted for seasonal variations in responses.

To identify factors associated with drug scene exposure and consider whether the level of exposure was associated with varying degrees of vulnerability to harm 
and adverse health outcomes, we constructed three separate regression models. All models used the "no exposure" category as the reference category. The first model considered the "low exposure" category, the second model considered the "moderate exposure" category, and the third model considered the "high exposure" category as the exposure of interest.

Since analyses of factors potentially associated with our outcomes of interest included serial measures for each subject, we used generalized estimating equations (GEE) for binary outcomes with logit link for the analysis of correlated data to determine factors associated with each level of drug scene exposure throughout the 40-month follow-up period. ${ }^{21}$ These methods provided standard errors adjusted by multiple observations per person using an exchangeable correlation structure. Therefore, data from every participant follow-up visit was considered in these analyses and we were able to accommodate changes in categories over time. Missing data was addressed through the GEE estimating mechanism which uses all available pairs method to encompass the missing data from dropouts or intermittent missing. ${ }^{21}$ All non-missing pairs of data are used in the estimators of the working correlation parameters.

As a first step, GEE univariate analyses were conducted to obtain unadjusted odds ratios and $95 \%$ confidence intervals for variables of interest and each level of drug scene exposure. In order to adjust for potential confounding, all variables that were associated with the dependent variable at $p<0.05$ in GEE univariate analyses were entered in each multivariate logistic GEE model. Although all multivariate models were run independently, all variables that reached significance at any level of drug scene exposure in univariate analyses were included in each multivariate model. This was to ensure that all three models adjusted for the same variables allowing for comparisons between multivariate models. All statistical analyses were performed using SAS software version 9.1. ${ }^{22}$ All $p$ values are two sided.

\section{RESULTS}

During the study period, a total of 1,486 participants completed follow-up visits, including $527(35 \%)$ women and $497(33 \%)$ persons who identified as being of Aboriginal ancestry. The median age of participants at baseline was 42 years (interquartile range $[\mathrm{IQR}]=35-48$ ). This sample contributed 3,994 observations; 1,237 observations fit the criteria for no exposure, 1,121 observations fit the criteria for low exposure, 779 observations fit the criteria for moderate exposure, and 757 observations fit the criteria for high drug scene exposure. The median number of follow-up visits was three (IQR $=2-4)$, and $1,157(77.9 \%)$ participants completed at least two study visits. The baseline characteristics of the study sample stratified by level of drug scene exposure are presented in Table 1 . In this baseline table, characteristics for individuals fitting the criteria for either low, moderate, or high drug scene exposure were measured at their first visit (during the study period, December 2005-March 2009), which involved a report of exposure. Characteristics for participants in the "no exposure" category were measured from the first study visit during the study period.

The univariate GEE analyses of behavioral and socio-demographic variables are presented in Table 2, and the multivariate GEE analyses are shown in Table 3. Figure 1 shows a selection of behavioral and drug use factors associated with each of the three levels of drug scene exposure (note, unstable housing was not 
TABLE 1 Baseline characteristics of sample stratified by level of drug scene exposure $(n=1,486)$

\begin{tabular}{|c|c|c|c|c|}
\hline \multirow[b]{2}{*}{ Characteristic $^{b}$} & \multicolumn{4}{|c|}{ Level of drug scene exposure ${ }^{a}$} \\
\hline & $\begin{array}{l}\text { No exposure } \\
n=490, n(\%)\end{array}$ & $\begin{array}{l}\text { Low exposure } \\
n=405, n(\%)\end{array}$ & $\begin{array}{l}\text { Moderate exposure } \\
n=277, n(\%)\end{array}$ & $\begin{array}{l}\text { High exposure } \\
n=314, n(\%)\end{array}$ \\
\hline Median age (IQR) & $43(36-49)$ & $43(38-49)$ & $42(35-48)$ & $38(31-44)$ \\
\hline Female gender & $183(37)$ & $136(34)$ & $91(33)$ & $117(37)$ \\
\hline Aboriginal ancestry & $139(28)$ & $129(32)$ & $98(35)$ & $131(42)$ \\
\hline Unstable housing ${ }^{c}$ & $219(45)$ & $325(80)$ & $237(86)$ & $302(96)$ \\
\hline Daily cocaine inject ${ }^{c}$ & $36(7)$ & $28(7)$ & $29(10)$ & $53(17)$ \\
\hline Daily heroin inject ${ }^{\mathrm{C}}$ & $79(16)$ & $70(17)$ & $88(32)$ & $149(47)$ \\
\hline Daily crack use ${ }^{c}$ & $119(24)$ & $146(36)$ & $152(55)$ & $212(68)$ \\
\hline Overdose $\left(\right.$ non-fatal) ${ }^{c}$ & $25(5)$ & $16(4)$ & $21(8)$ & $31(10)$ \\
\hline Syringe sharing ${ }^{c}$ & $46(9)$ & $24(6)$ & $17(6)$ & $33(11)$ \\
\hline Encounters with police ${ }^{d}$ & $80(16)$ & $92(23)$ & $106(38)$ & $144(46)$ \\
\hline Victim of violence ${ }^{c}$ & $58(12)$ & $83(20)$ & $79(29)$ & $93(30)$ \\
\hline Multiple sex partner ${ }^{c}$ & $64(13)$ & $69(17)$ & $64(23)$ & $75(24)$ \\
\hline Unprotected sex ${ }^{c}$ & $161(33)$ & $123(30)$ & $89(32)$ & $87(28)$ \\
\hline Regular employment $^{c}$ & $175(36)$ & $88(22)$ & $62(22)$ & $45(14)$ \\
\hline Sex work ${ }^{c}$ & $38(8)$ & $59(15)$ & $48(17)$ & $58(18)$ \\
\hline Drug dealing ${ }^{\mathrm{C}}$ & $90(18)$ & $98(24)$ & $112(40)$ & $169(54)$ \\
\hline In treatment ${ }^{c}$ & $277(57)$ & $222(55)$ & $115(42)$ & $120(38)$ \\
\hline
\end{tabular}

${ }^{a}$ Levels of drug scene exposure were defined based on the average number of hours participants reported spending on the street each day in Vancouver's drug use epicenter in the previous 6 months: "no drug scene exposure" included reports of 1 hour or less, "low exposure" included reports of 2-6 hours, "moderate exposure" included reports of 7-15 hours, and "high exposure" included reports of more than 15 hours

${ }^{b}$ Characteristics for individuals in the low, moderate, and high drug scene exposure categories were measured at their first visit (during the study period, December 2005-March 2009), which involved a report of drug scene exposure. Characteristics for participants in the "no exposure" category were measured from the first study visit during the study period

${ }^{c}$ Activities or situations referring to the previous 6 months

${ }^{\mathrm{d}}$ Activities or situations referring to the previous month

included in the figure due to the large scale difference in adjusted odds ratio, AOR). In multivariate analyses, unstable housing was significantly associated with all levels of drug scene exposure and the strength of the association increased from low $(\mathrm{AOR}=3.10$; $\mathrm{CI}, 2.52-3.80)$ to moderate $(\mathrm{AOR}=3.73$; CI, 2.92-4.77) to high exposure $(\mathrm{AOR}=9.50$; CI, 6.36-14.20). Similarly, the associations between drug scene exposure and drug use practices increased with level of exposure. Daily crack cocaine use was significantly associated with all levels of drug scene exposure and this association increased from low (AOR= 1.49 ; CI, 1.20-1.85) to moderate $(\mathrm{AOR}=1.90 ; \mathrm{CI}, 1.50-2.40)$ to high exposure $(\mathrm{AOR}=2.70 ; \mathrm{CI}, 2.07-3.52)$. Daily heroin injection was not significantly associated with low drug scene exposure $(\mathrm{AOR}=0.82$; CI, 0.63-1.08), but became significantly associated with moderate exposure (AOR $=1.43$; CI, 1.071.91), and the strength of association increased with high exposure (AOR $=1.84$; CI, 1.37-2.47). Daily cocaine injection was not significantly associated with low (AOR=0.87; CI, 0.60-1.26) or moderate drug scene exposure (AOR=1.09; CI, 0.72-1.64), but became significant with high exposure (AOR=1.73; CI, 1.152.61). Likewise, being a victim of violence, having encounters with police, and 
TABLE 2 Univariate analyses of factors associated with drug scene exposure

\begin{tabular}{|c|c|c|c|c|c|c|}
\hline \multirow[b]{2}{*}{ Characteristic } & \multicolumn{2}{|l|}{$\begin{array}{l}\text { GEE for low vs. } \\
\text { no Exposure }\end{array}$} & \multicolumn{2}{|c|}{$\begin{array}{l}\text { GEE for moderate vs. } \\
\text { no exposure }\end{array}$} & \multicolumn{2}{|l|}{$\begin{array}{l}\text { GEE for high vs. } \\
\text { no exposure }\end{array}$} \\
\hline & $\begin{array}{l}\text { OR } \\
(95 \% \mathrm{Cl})\end{array}$ & $p$ value & $\begin{array}{l}\text { OR } \\
(95 \% \mathrm{Cl})\end{array}$ & $p$ value & $\begin{array}{l}\text { OR } \\
(95 \% \mathrm{Cl})\end{array}$ & $p$ value \\
\hline $\begin{array}{l}\text { Older age } \\
\text { Per year older }\end{array}$ & $1.00(0.99-1.02)$ & 0.457 & $0.99(0.97-1.00)$ & 0.017 & $0.95(0.93-0.96)$ & $<0.001$ \\
\hline $\begin{array}{l}\text { Gender } \\
\text { Female vs. male }\end{array}$ & $0.87(0.71-1.07)$ & 0.183 & $0.95(0.76-1.19)$ & 0.659 & $1.03(0.81-1.30)$ & 0.836 \\
\hline $\begin{array}{l}\text { Aboriginal ancestry } \\
\text { Yes vs. no }\end{array}$ & $1.11(0.90-1.36)$ & 0.330 & $1.34(1.06-1.68)$ & 0.013 & $1.52(1.19-1.93)$ & $<0.001$ \\
\hline $\begin{array}{l}\text { Unstable housing }^{a} \\
\text { Yes vs. no }\end{array}$ & $3.29(2.71-4.01)$ & $<0.001$ & $4.22(3.36-5.31)$ & $<0.001$ & 11.25 (7.97-15.88) & $<0.001$ \\
\hline $\begin{array}{l}\text { Daily cocaine inject }{ }^{\mathrm{a}} \\
\text { Yes vs. no }\end{array}$ & $1.07(0.76-1.51)$ & 0.680 & $1.37(0.99-1.91)$ & 0.060 & $1.95(1.46-2.59)$ & $<0.001$ \\
\hline $\begin{array}{l}\text { Daily heroin inject }{ }^{a} \\
\text { Yes vs. no }\end{array}$ & $0.99(0.78-1.27)$ & 0.963 & $2.19(1.71-2.80)$ & $<0.001$ & $3.09(2.45-3.89)$ & $<0.001$ \\
\hline $\begin{array}{l}\text { Daily crack use }{ }^{a} \\
\text { Yes vs. no }\end{array}$ & $1.87(1.53-2.27)$ & $<0.001$ & $2.71(2.20-3.33)$ & $<0.001$ & $4.09(3.32-5.04)$ & $<0.001$ \\
\hline Overdose (non-fatal) ${ }^{\mathrm{a}}$ & $0.74(0.49-1.12)$ & 0.152 & $1.32(0.94-1.87)$ & 0.108 & $1.38(1.04-1.84)$ & 0.026 \\
\hline $\begin{array}{l}\text { Yes vs. no } \\
\text { Syringe sharing }\end{array}$ & $0.96(0.68-1.33)$ & 0.788 & $1.19(0.84-1.68)$ & 0.318 & $1.16(0.86-1.56)$ & 0.331 \\
\hline $\begin{array}{l}\text { Yes vs. no } \\
\text { Encounters with police }\end{array}$ & $1.36(1.10-1.69)$ & 0.004 & $2.01(1.63-2.48)$ & $<0.001$ & $2.30(1.88-2.82)$ & $<0.001$ \\
\hline $\begin{array}{l}\text { Yes vs. no } \\
\text { Victim of violence }\end{array}$ & $1.22(0.97-1.53)$ & 0.092 & $1.76(1.45-2.13)$ & $<0.001$ & $1.70(1.42-2.02)$ & $<0.001$ \\
\hline $\begin{array}{l}\text { Yes vs. no } \\
\text { Multiple sex partners }\end{array}$ & $1.09(0.86-1.38)$ & 0.477 & $1.34(1.05-1.72)$ & 0.019 & $1.44(1.17-1.78)$ & $<0.001$ \\
\hline $\begin{array}{l}\text { Yes vs. no } \\
\text { Unprotected sex }\end{array}$ & $0.88(0.73-1.06)$ & 0.176 & $0.92(0.76-1.12)$ & 0.420 & $0.92(0.76-1.10)$ & 0.347 \\
\hline $\begin{array}{l}\text { Yes vs. no } \\
\text { Regular employment }{ }^{\text {a }} \\
\text { Yes vs. no }\end{array}$ & $0.67(0.55-0.81)$ & $<0.001$ & $0.61(0.50-0.75)$ & $<0.001$ & $0.47(0.39-0.57)$ & $<0.001$ \\
\hline $\begin{array}{l}\text { Sex work }{ }^{\mathrm{a}} \\
\text { Yes ys, no }\end{array}$ & $1.70(1.29-2.23)$ & $<0.001$ & $1.99(1.50-2.65)$ & $<0.001$ & $2.09(1.56-2.79)$ & $<0.001$ \\
\hline Drug dealing ${ }^{\mathrm{a}}$ & $1.37(1.12-1.67)$ & 0.002 & $2.06(1.66-2.55)$ & $<0.001$ & $2.91(2.40-3.55)$ & $<0.001$ \\
\hline $\begin{array}{l}\text { Yes vs. no } \\
\text { Addiction treatment }^{\mathrm{a}} \\
\text { Yes vs. no }\end{array}$ & $1.10(0.92-1.30)$ & 0.293 & $0.75(0.63-0.91)$ & 0.003 & $0.68(0.56-0.82)$ & $<0.001$ \\
\hline
\end{tabular}

Levels of drug scene exposure were defined based on the number of hours participants reported spending on average on the street each day in Vancouver's drug use epicenter in the previous 6 months: "no drug scene exposure" included reports of 1 hour or less, "low exposure" included reports of 2-6 hours, "moderate exposure" included reports of 7-15 hours, and "high exposure" included reports of more than 15 hours

GEE generalized estimating equation, $O R$ odds ratio, $\mathrm{Cl}$ confidence interval

${ }^{\mathrm{a}}$ Activities or situations referring to the previous 6 months

${ }^{\mathrm{b}}$ Activities or situations referring to previous month

involvement in drug dealing were not associated with low drug scene exposure, but became significant for both moderate and high exposure (see Table 3). Aboriginal ancestry also was not significantly associated with low drug scene exposure, but became significant with both moderate and high exposure. Regular employment was significantly negatively associated with all levels of drug scene exposure. Although addiction treatment was not significantly associated with low drug scene exposure, it became significantly negatively associated with moderate and high exposure. 
TABLE 3 Multivariate analyses of factors associated with drug scene exposure

\begin{tabular}{|c|c|c|c|c|c|c|}
\hline \multirow[b]{2}{*}{ Characteristic } & \multicolumn{2}{|c|}{ GEE for low vs. no exposure } & \multicolumn{2}{|c|}{ GEE for moderate vs. no exposure } & \multicolumn{2}{|c|}{ GEE for high vs. no exposure } \\
\hline & AOR $(95 \% \mathrm{Cl})$ & $p$ value & AOR $(95 \% \mathrm{Cl})$ & $p$ value & AOR $(95 \% \mathrm{Cl})$ & $p$ value \\
\hline Older age & $1.01(1.00-1.02)$ & 0.071 & $1.00(0.99-1.02)$ & 0.684 & $0.97(0.96-0.99)$ & $<0.001$ \\
\hline \multicolumn{7}{|l|}{ Per year older } \\
\hline Aboriginal ancestry & $1.19(0.96-1.48)$ & 0.105 & $1.52(1.18-1.95)$ & 0.001 & $1.74(1.30-2.34)$ & $<0.001$ \\
\hline \multicolumn{7}{|l|}{ Yes vs. no } \\
\hline Unstable housing $^{\mathrm{a}}$ & $3.10(2.52-3.80)$ & $<0.001$ & $3.73(2.92-4.77)$ & $<0.001$ & $9.50(6.36-14.20)$ & $<0.001$ \\
\hline \multicolumn{7}{|l|}{ Yes vs. no } \\
\hline Daily cocaine inject ${ }^{\mathrm{a}}$ & $0.87(0.60-1.26)$ & 0.461 & $1.09(0.72-1.64)$ & 0.680 & $1.73(1.15-2.61)$ & 0.009 \\
\hline \multicolumn{7}{|l|}{ Yes vs. no } \\
\hline \multicolumn{6}{|l|}{ Yes vs. no } & $<0.001$ \\
\hline $\begin{array}{l}\text { Daily crack use }{ }^{a} \\
\text { Yes vs. no }\end{array}$ & $1.49(1.20-1.85)$ & $<0.001$ & $1.90(1.50-2.40)$ & $<0.001$ & $2.70(2.07-3.52)$ & $<0.001$ \\
\hline Overdose (non-fatal) ${ }^{a}$ & $0.62(0.40-0.96)$ & 0.031 & $0.94(0.62-1.44)$ & 0.783 & $0.85(0.57-1.25)$ & 0.400 \\
\hline \multicolumn{7}{|l|}{ Yes vs. no } \\
\hline $\begin{array}{l}\text { Encounters with police } \\
\text { Yes vs. no }\end{array}$ & $1.25(0.99-1.57)$ & 0.061 & $1.63(1.28-2.08)$ & $<0.001$ & Yes vs. no & $<0.001$ \\
\hline Victim of violence $^{a}$ & $1.12(0.88-1.44)$ & 0.365 & $1.50(1.19-1.89)$ & $<0.001$ & $1.49(1.14-1.95)$ & 0.003 \\
\hline \multicolumn{7}{|l|}{ Yes vs. no } \\
\hline $\begin{array}{l}\text { Multiple sex partners } \\
\text { Yes vs. no }\end{array}$ & $1.05(0.82-1.36)$ & 0.693 & $1.11(0.83-1.49)$ & 0.489 & Yes vs. no & 0.341 \\
\hline $\begin{array}{l}\text { Regular employment }^{\mathrm{a}} \\
\text { Yes vs. no }\end{array}$ & $0.77(0.63-0.94)$ & 0.010 & $0.75(0.60-0.95)$ & 0.015 & $0.50(0.38-0.65)$ & $<0.001$ \\
\hline $\begin{array}{l}\text { Sex } \text { work }^{\mathrm{a}} \\
\text { Yes vs. no }\end{array}$ & $1.44(1.08-1.92)$ & 0.013 & $1.63(1.20-2.21)$ & 0.002 & $1.28(0.88-1.86)$ & 0.202 \\
\hline Drug dealing ${ }^{\mathrm{a}}$ & $1.05(0.84-1.33)$ & 0.655 & $1.35(1.05-1.73)$ & 0.019 & $1.46(1.14-1.87)$ & 0.003 \\
\hline Yes vs. no & & & & & & \\
\hline $\begin{array}{l}\text { Addiction treatment }^{\mathrm{a}} \\
\text { Yes vs. no }\end{array}$ & $1.04(0.86-1.25)$ & 0.688 & $0.69(0.56-0.85)$ & $<0.001$ & $0.58(0.45-0.75)$ & $<0.001$ \\
\hline
\end{tabular}

Levels of drug scene exposure were defined based on the number of hours participants reported spending on average on the street each day in Vancouver's drug use epicenter in the previous 6 months: "no drug scene exposure" included reports of 1 hour or less, "low exposure" included reports of 2-6 hours, "moderate exposure" included reports of 7-15 hours, and "high exposure" included reports of more than 15 hours

All models were adjusted for the month each interview was conducted

GEE generalized estimating equation, $A O R$ adjusted odds ratio, $\mathrm{Cl}$ confidence interval

${ }^{a}$ Activities or situations referring to the previous 6 months

${ }^{\mathrm{b}}$ Activities or situations referring to the previous month

\section{DISCUSSION}

In this study, we found that drug scene exposure was associated in a dose-dependent fashion with multiple markers of vulnerability to harm and adverse health outcomes, including being unstably housed, being a victim of violence, having encounters with police, and participating in drug dealing. Drug scene exposure was also associated with higher-intensity drug use. Individuals who reported high levels of drug scene exposure were significantly more likely to inject cocaine and heroin on a daily basis, and daily crack cocaine use was significantly associated with all levels of drug scene exposure. These associations, in most instances, also increased in a dose-dependent fashion with greater exposure to drug scenes. The dose-dependent effect was particularly strong for unstable housing, intensity of drug use, and encounters with police. Our analysis further found that employment and addiction treatment were associated with decreased drug scene exposure. 


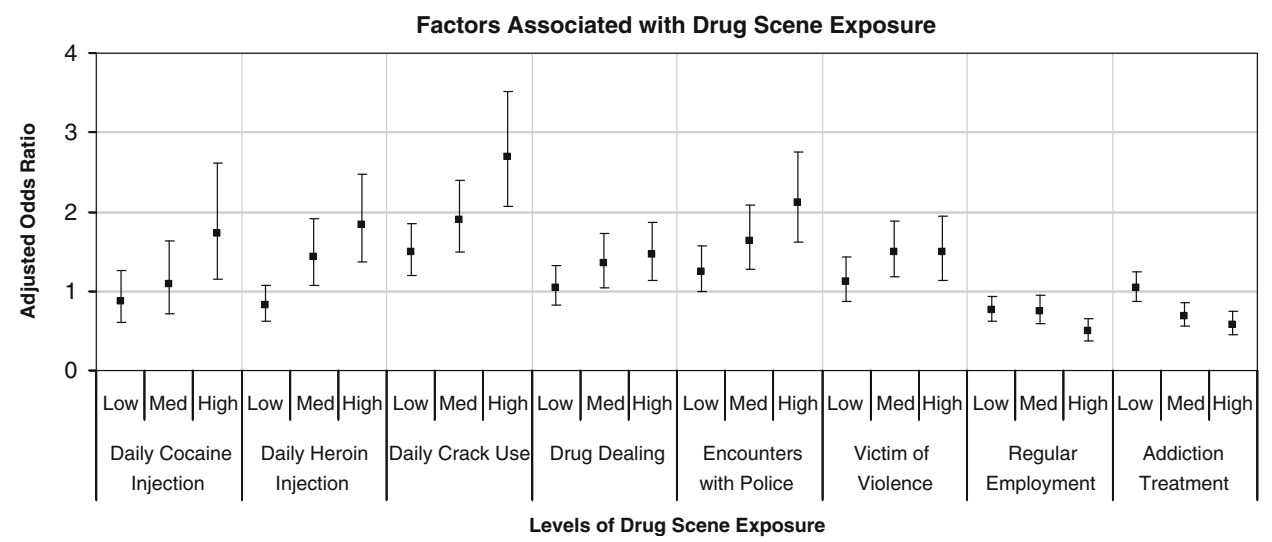

FIGURE 1. Levels of drug scene exposure were defined based on the number of hours participants reported spending on average on the street each day in Vancouver's drug use epicenter in the previous 6 months. All above estimates used the reference category of "no drug scene exposure" defined as spending 1 hour or less in Vancouver's drug scene. "Low exposure" included reports of 26 hours, "moderate exposure" included reports of 7-15 hours, and "high exposure" included reports of more than 15 hours. All models were adjusted for and included the following variables: age, Aboriginal ancestry, unstable housing, daily cocaine injection, daily heroin injection, daily crack cocaine use, drug overdose, encounters with police, victim of violence, multiple sex partners, regular employment, sex work, drug dealing, addiction treatment, and month interview was conducted.

Our finding that people with greater levels of drug scene exposure were more likely to be higher intensity drug users and have multiple markers of vulnerability is consistent with a broader literature highlighting the relationship between structural environmental factors (e.g., drug use settings, and the laws and policies regulating drug use) and health behaviors and outcomes. ${ }^{23-25}$ However, previous work looking at the impact of drugs scenes has historically focused on involvement in drug scenes in the context of specific behaviors such as income generation acts, $, 6,7,9,16$ public injecting, ${ }^{4,18}$ and drug scene roles. ${ }^{10}$ Our study is unique in that it considers exposure to drug scenes independent of engagement in specific activities.

A key implication of our findings is that the negative impacts of street-based drug scenes are not felt only by surrounding communities and the general public. Rather, street-based drug scenes have significant negative health and social implications for people who are exposed to them and these negative effects appear to increase with greater levels of drug scene exposure. This suggests that efforts to reduce street disorder have potential to benefit people who are engaged in drug scenes, as well as the broader community.

It is important to recognize that, to date, interventions to address drug-related street disorder have largely relied on law enforcement approaches that have been shown to be limited in their ability to meaningfully address street disorder. ${ }^{26-30}$ Furthermore, many law enforcement-based strategies have also been linked with negative individual and community outcomes. ${ }^{31-33}$ Innovative solutions that both reduce drug-related street disorder and protect the health of people who are engaged in drug scenes are therefore required.

In the current analysis, the relationship between employment and reduced drug scene exposure is consistent with previous research demonstrating the positive influence of employment on social integration and health outcomes ${ }^{34,35}$ 
and suggests that interventions in this area may help to address street disorder and drug scene exposure. However, existing employment programs for people who use drugs are often linked with addiction treatment objectives and intended to engage participants in regular steady employment and abstinence from illicit drug use. ${ }^{34,36}$ These programmatic conditions and goals are not suitable or realistic for many street-entrenched drug users. ${ }^{37,38}$ Alternatively, low-threshold employment programs that do not require abstinence from drug use may provide important benefits for injection drug users (IDU) including a reduction in exposure to street-based drug scenes. ${ }^{38-40}$ The potential relationship between street disorder and low-threshold employment is an area that should be considered for future study.

Our findings related to unstable housing provide additional direction for the development of policy options that might help to address exposure to street disorder. Specifically, providing stable housing to homeless people who use drugs is one promising approach to decrease street disorder and exposure to drug scenes. However, it is notable that in addition to outright homelessness, our definition of unstable housing included living in single room occupancy hotels as well as treatment and recovery homes, suggesting that it is not just people who are homeless who are generating street disorder. For instance, space constraints and regulatory policies within single-room occupancy hotels and recovery houses (i.e., guest fees and bans on substance use and/or intoxication on the premises) may deter drug users from spending time in their place of residence and thereby contribute to street disorder. ${ }^{41}$ Further examination of the role that space constraints and restrictive regulatory policies may play in encouraging exposure to drug scenes would be beneficial.

Finally, our finding that those more involved in the local drug scene were less likely to be receiving addiction treatment suggests that efforts to encourage access and engagement in addiction treatment may further help to reduce street disorder. Innovative addiction treatment methods may be required as the long-term drug use patterns of IDU suggest that current treatment modalities have limited success in sustaining injection cessation among a large proportion of established IDU. ${ }^{42}$ Furthermore, the rapid increase in crack cocaine use in our study setting and elsewhere suggests that addiction treatment for stimulant users is an emerging priority. In the Vancouver setting, our analysis also suggests that to be effective, interventions must be culturally sensitive and appropriate for Aboriginal people who use drugs. This will likely require tailoring interventions with the direct input of drug users who identify as being of Aboriginal ancestry.

There are a number of limitations in our study. Firstly, our study sample was community recruited and not a random sample of people who inject drugs. It is, however, believed to be reflective of the population of injection drug users in the community. ${ }^{43}$ Secondly, although the current study shows that drug scene exposure is associated with multiple risk factors for negative health outcomes, the nature of our observational study cannot untangle whether these relationships are revealing antecedent causes or consequences of exposure to drug scenes. With respect to antecedent causes, the relationship between housing and drug scene exposure is consistent with a well-established literature demonstrating that housing is a key influence on health status among drug-using populations. ${ }^{44-47}$ In our study context, unstable housing conditions (which included outright homelessness) may lead to exposure to and immersion in open drug scenes. However, individuals who are stably housed may become involved in open drug scenes through other mechanisms and this immersion may have a destabilizing influence that could lead to 
deterioration in housing status. Similarly, our analyses cannot determine whether the elevated intensity of drug use that coincides with exposure is because highintensity drug use predisposes individuals to become immersed in open drug scenes, or if exposure to drug scenes leads to heightened drug use. Furthermore, although none of our explanatory variables of interest are by definition street disorder, our analysis included variables such as unstable housing and drug dealing that can be considered both as indicators of street disorder, as well as markers of vulnerability to harm. Regardless of whether street disorder creates harm, is associated with harm, or is harmful itself, our findings clearly show that individuals who spend more time in the open drug scene are a high-risk population that should be targeted for interventions. Efforts to reduce drug scene exposure and engagement in activities that generate street disorder appear to be important policy and public health objectives. Another limitation of our study is that several of our measures are based on self-report and are hence vulnerable to socially desirable responding and recall bias. In the current study, socially desirable responding may have led to an underestimation of risk behavior and exposure to drug scenes suggesting that our estimates are conservative. Although recall issues are particularly relevant to our measures for exposure to street disorder, we have no reason to suspect this would systematically differ among exposures of interest. Therefore, if recall issues are present, we would suspect this would bias our results towards the null.

In summary, increasing exposure to street-based drug scenes is associated with increasing vulnerability and intensity of addiction, suggesting that both individual drug users and surrounding communities are negatively impacted by street disorder. This suggests that reducing street disorder and exposure to it can have a wide range of public health and community benefits. These findings highlight important opportunities for policy interventions to address exposure to street disorder in the areas of employment, housing, and addiction treatment.

\section{ACKNOWLEDGMENTS}

The authors thank the study participants for their contribution to the research, as well as current and past researchers and staff. We would specifically like to thank Deborah Graham, Tricia Collingham, Carmen Rock, Peter Vann, Caitlin Johnston, Steve Kain, and Calvin Lai for their research and administrative assistance. The study was supported by the US National Institutes of Health (R01DA011591) and (R01DA021525) and the Canadian Institutes of Health Research (MOP-79297, RAA-79918). Thomas Kerr is supported by the Michael Smith Foundation for Health Research and the Canadian Institutes of Health Research. Kora DeBeck is supported by a Michael Smith Foundation for Health Research Senior Graduate Trainee Award and a Canadian Institutes of Health Research Doctoral Research Award. Julio Montaner has received an AvantGarde award (DP1DA026182) from the National Institute of Drug Abuse, US National Institutes of Health.

OPEN ACCESS This article is distributed under the terms of the Creative Commons Attribution Noncommercial License which permits any noncommercial use, distribution, and reproduction in any medium, provided the original author(s) and source are credited. 


\section{REFERENCES}

1. Cusick L, Kimber J. Public perceptions of public drug use in four UK urban sites. Int J Drug Policy. 2007; 18: 10-7.

2. Skogan WG. Disorder and decline: crime and the spiral of decay in American neighborhoods. Berkeley, CA: Free Press; 1990.

3. Weisburd D, Mazerolle LG. Crime and disorder in drug hot spots: implications for theory and practice in policing. Police Q. 2000; 3: 331.

4. Navarro C, Leonard L. Prevalence and factors related to public injecting in Ottawa, Canada: implications for the development of a trial safer injecting facility. Int J Drug Policy. 2004; 15: 275-84.

5. Sampson RJ, Raudenbush SW. Systematic social observation of public spaces: a new look at disorder in urban neighborhoods. Am J Sociol. 1999; 105: 603-51.

6. Shannon K, Bright V, Gibson K, Tyndall MW, Maka Project Partnership. Sexual and drug-related vulnerabilities for HIV infection among women engaged in survival sex work in Vancouver, Canada. Can J Public Health. 2007; 98: 465-9.

7. Kerr T, Small W, Johnston C, Li K, Montaner JS, Wood E. Characteristics of injection drug users who participate in drug dealing: implications for drug policy. $J$ Psychoactive Drugs. 2008; 40: 147-52.

8. Bose R, Hwang SW. Income and spending patterns among panhandlers. Can Med Assoc J. 2002; 167: 477-9.

9. DeBeck K, Shannon K, Wood E, Li K, Montaner J, Kerr T. Income generating activities of people who inject drugs. Drug Alcohol Depend. 2007; 91: 50-6.

10. Friedman SR, Furst RT, Jose B, et al. Drug scene roles and HIV risk. Addiction. 1998; 93: 1403-16.

11. Falcato L, Stohler R, Dursteler-Mac Farland KM, Eichenberger A, Eich D, Rossler W. Closure of an open drug scene-a case register-based analysis of the impact on the demand for methadone maintenance treatment. Addiction. 2001; 96: 623-8.

12. Mitchell D. The annihilation of space by law: the roots and implications of anti-homeless laws in the United States. Radic J Geography. 1997; 29: 303-35.

13. Johnson BD, Williams T, Dei KA, Sanabria H. Drug abuse in the inner city: impact on harddrug users and the community. Crime and Justice: A Review of Research. 1990; 13: 9.

14. Punch M. Problem drug use and the political economy of urban restructuring: heroin, class and governance in Dublin. Antipode. 2005; 37: 754-74.

15. Tempalski B, McQuie H. Drugscapes and the role of place and space in injection drug use-related HIV risk environments. Int J Drug Policy. 2009; 20: 4-13.

16. Maher L. Sexed work: gender, race, and resistance in a Brooklyn drug market. New York, NY: Oxford University Press; 2000.

17. Rhodes T, Kimber J, Small W, et al. Public injecting and the need for 'safer environment interventions' in the reduction of drug-related harm. Addiction. 2006; 101: 1384-93.

18. Small W, Rhodes T, Wood E, Kerr T. Public injection settings in Vancouver: physical environment, social context and risk. Int J Drug Policy. 2007; 18: 27-36.

19. Wood E, Tyndall MW, Spittal PM, et al. Factors associated with persistent high-risk syringe sharing in the presence of an established needle exchange programme. AIDS. 2002; 16: 941-3.

20. Kerr T, Wood E, Small D, Palepu A, Tyndall MW. Potential use of safer injecting facilities among injection drug users in Vancouver's downtown eastside. Can Med Assoc J. 2003; 169: 759.

21. Liang KY, Zeger SL. Longitudinal data analysis using generalized linear models. Biometrika. 1986; 73: 13.

22. SAS Institute Inc. SAS ${ }^{\circledR}$ 9.1.3 Intelligence platform: single-user installation guide. Cary, NC: SAS Institute Inc.; 2005.

23. Blankenship K, Bray S, Merson M. Structural interventions in public health. AIDS. 2000; 14: S11-21.

24. Galea S, Ahern J, Vlahov D. Contextual determinants of drug use risk behavior: a theoretic framework. J Urban Health. 2003; 80: iii50-8. 
25. Rhodes T, Singer M, Bourgois P, Friedman SR, Strathdee SA. The social structural production of HIV risk among injecting drug users. Soc Sci Med. 2005; 61: 1026-44.

26. Aitken C, Moore D, Higgs P, Kelsall J, Kerger M. The impact of a police crackdown on a street drug scene: evidence from the street. Int J Drug Policy. 2002; 13: 189-98.

27. Maher L, Dixon D. Policing and public health: law enforcement and harm minimization in a street-level drug market. Brit J Criminol. 1999; 39: 488-512.

28. Boyum D, Reuter P. An analytic assessment of US drug policy. Washington, DC: American Enterprise Institute for Public Policy Research; 2005.

29. Annual report: The state of the drugs problem in Europe. Lisbon, Portugal: European Monitoring Centre for Drugs and Drug Addiction; 2005.

30. National Research Council. Executive summary of the National Research Council's report informing America's policy on illegal drugs: what we don't know keeps hurting us. Addiction. 2002; 97: 647-52.

31. Shannon K, Strathdee SA, Shoveller J, Rusch M, Kerr T, Tyndall MW. Structural and environmental barriers to condom use negotiation with clients among female sex workers: implications for HIV-prevention strategies and policy. Am J Public Health. 2009; 99: 659-65.

32. Small W, Kerr T, Charette J, Schechter MT, Spittal PM. Impacts of intensified police activity on injection drug users: evidence from an ethnographic investigation. Int J Drug Policy. 2006; 17: 85-95.

33. Roberts DE. Race, vagueness, and the social meaning of order-maintenance policing. $J$ Crim Law Criminol. 1998; 89: 775.

34. Platt JJ. Vocational rehabilitation of drug abusers. Psychol Bull. 1995; 117: 416-33.

35. Magura S, Staines GL, Blankertz L, Madison EM. The effectiveness of vocational services for substance users in treatment. Subst Use Misuse. 2004; 39: 2165-213.

36. Magura $S$. The role of work in substance dependency treatment: a preliminary overview. Subst Use Misuse. 2003; 38: 1865-76.

37. McCoy CB, Comerford M, Metsch LR. Employment among chronic drug users at baseline and 6-month follow-up. Subst Use Misuse. 2007; 42: 1055-67.

38. Sherman S, German D, Cheng Y, Marks M, Bailey-Kloche M. The evaluation of the JEWEL project: an innovative economic enhancement and HIV prevention intervention study targeting drug using women involved in prostitution. AIDS Care. 2006; $18: 1$.

39. Dale A, Newman L. Social capital: a necessary and sufficient condition for sustainable community development? Community Dev J. 2008; 45: 5-21.

40. Lo J, Halseth G. The practice of principles: an examination of CED groups in Vancouver. BC Community Dev J. 2009; 44: 80.

41. O'Shaughnessy M, Montaner J, Strathdee S, Schechter M. Deadly public policy. Int Conf AIDS. 1998; 12: 982. -abstract no. 44233.

42. Galai N, Safaeian M, Vlahov D, Bolotin A, Celentano D. Longitudinal patterns of drug injection behavior in the ALIVE study cohort, 1988-2000: description and determinants. Am J Epidemiol. 2003; 158: 695-704.

43. Tyndall MW, Craib KJP, Currie S, Li K, O’Shaughnessy MV, Schechter MT. Impact of HIV infection on mortality in a cohort of injection drug users. JAIDS J Acquired Immune Defic Syndromes. 2001; 28: 351.

44. Aidala A, Cross JE, Stall R, Harre D, Sumartojo E. Housing status and HIV risk behaviors: implications for prevention and policy. AIDS Behav. 2005; 9: 251-65.

45. Aidala AA, Sumartojo E. Why housing? AIDS Behav. 2007; 11: 1-6.

46. Hwang SW. Homelessness and health. CMAJ. 2001; 164: 229-33.

47. Krieger J, Higgins DL. Housing and health: time again for public health action. Am J Public Health. 2002; 92: 758-68. 